Article

\title{
Electrospun Phospholipid Fibers as Micro-Encapsulation and Antioxidant Matrices
}

\author{
Elhamalsadat Shekarforoush ${ }^{1}$, Ana C. Mendes ${ }^{1, *}$ (D), Vanessa Baj ${ }^{2}$, Sophie R. Beeren ${ }^{2}$ (D) and \\ Ioannis S. Chronakis ${ }^{1}$ \\ 1 Nano-Bio Science Research Group, DTU-Food, Technical University of Denmark, Kemitorvet 202, \\ 2800 Kongens Lyngby, Denmark; elsh@food.dtu.dk (E.S.); ioach@food.dtu.dk (I.S.C.) \\ 2 DTU-Chemistry, Technical University of Denmark, Kemitorvet 207, 2800 Kongens Lyngby, Denmark; \\ vanbaj@kemi.dtu.dk (V.B.); sopbee@kemi.dtu.dk (S.R.B.) \\ * Correspondence: anac@food.dtu.dk; Tel.: +45-9351-8947
}

Received: 9 September 2017; Accepted: 9 October 2017; Published: 17 October 2017

\begin{abstract}
Electrospun phospholipid (asolectin) microfibers were investigated as antioxidants and encapsulation matrices for curcumin and vanillin. These phospholipid microfibers exhibited antioxidant properties which increased after the encapsulation of both curcumin and vanillin. The total antioxidant capacity (TAC) and the total phenolic content (TPC) of curcumin/phospholipid and vanillin/phospholipid microfibers remained stable over time at different temperatures (refrigerated, ambient) and pressures (vacuum, ambient). ${ }^{1} \mathrm{H}-\mathrm{NMR}$ confirmed the chemical stability of both encapsulated curcumin and vanillin within phospholipid fibers. Release studies in aqueous media revealed that the phenolic bioactives were released mainly due to swelling of the phospholipid fiber matrix over time. The above studies confirm the efficacy of electrospun phospholipid microfibers as encapsulation and antioxidant systems.
\end{abstract}

Keywords: phospholipids; electrospinning; microfibers; antioxidants; encapsulation; vanillin; curcumin

\section{Introduction}

Phospholipids have been used for preparing biomimetic capsular structures (mainly vesicles or liposomes) [1-4], for several life science applications, including nano-micro encapsulation of drugs [5] and mammalian cells [6], and in food [7] as delivery carriers of nutrients, nutraceuticals, food additives and antimicrobials. Encapsulation of bioactives within lipid formulations often offers enhanced stability and protection, combined with superior biocompatibility and enhanced permeability, depending on the lipid composition and properties [8,9]. Among other phospholipids, asolectin, constituted by a mixture of lecithin, cephalin and phosphatidylinositol, saturated fatty acids, mono-unsaturated and poly-unsaturated fatty acids has been used to develop nano-microstructures such as fibers [10-13], hydrogels [14] and liposomes [7,15] for the encapsulation of bioactives [13,16]. In addition, asolectin components have also been proven to display antioxidant properties [16-19]. Pan and co-workers [16] evaluated the effect of the antioxidant properties of lecithin emulsifier on the oxidative stability of encapsulated bioactive compounds. They demonstrated that the antioxidant activity of lecithin emulsifier can significantly reduce the saturation of free radicals across the interface of oil-in-water emulsions, as well as the rate of oxidation of the bioactive encapsulate (curcumin), thus increasing its shelf life. The antioxidant effect of lecithins was also tested on several oils and fats varying in FA composition and tocopherol content [17]. They found that lecithins, at specific concentrations, exhibited a good protective effect against oxidation on several oils and fats with varying FA composition. These antioxidant properties were enhanced in samples containing tocopherols, due to the synergistic interactions between amino-alcohol phospholipids and $\gamma$-and $\delta$-tocopherols. 
Furthermore, Doert and co-authors [20] studied the synergistic effect of lecithins with tocopherols and observed that phospholipids synergistically enhance the antioxidant effect of phenolic antioxidants.

Phenolic compounds are known for the inhibition of free radical formation and/or for the interruption of the propagation of autoxidation [21]. Vanillin (4-hydroxy-3-methoxybenzaldehyde) is a phenolic compound, which can either be extracted from pods of Vanilla Planifolia or synthesized chemically, and has been widely used in the food industry as a flavor, but also as a food preservative, due to its antioxidant, antimicrobial, anticarcinogenic and antimutagenic properties [22,23]. However, its high volatility and thermal instability are the main drawbacks for its use and processing. Curcumin is another phenolic compound derived from the turmeric of the herb Curcuma longa L., with biological and pharmacological properties, such as antioxidant, anti-inflammatory, antimicrobial, antimalarial, and anticarcinogenic properties [24]. Due to its hydrophobic nature, curcumin has very low solubility in water and its chemical stability has been reported to be affected by external factors such as $\mathrm{pH}$, exposure to light, temperature and oxygen $[25,26]$. Curcumin has poor bioavailability due to inefficient absorption at the intestinal track and for that reason it is commonly administered with digestible lipids that facilitate the solubilization and transport of this phenolic compound to the epithelial tissue [25].

Electrospinning processing is suitable for the production of continuous and functional nano-microfibers, from a wide range of (bio)polymers [27] and small molecules such as phospholipids [10-12]. The fabrication of electrospun phospholipid fibers has been initially reported using DMF: $\mathrm{CHCl}_{3}$ solvents [11]. Recently, it was demonstrated that the morphological properties of electropsun phospholipid fibers could be controlled using solvents with different polarities such as isooctane, cyclohexane and limonene and by the application of a co-axial solvent electrospinning [11]. The mechanical properties of phospholipid microfibers were investigated by nanoindentation using Atomic Force Microscopy [12]. It was found that these fibers have an elastic modulus of $17.26 \mathrm{MPa}$ and were stable in ambient conditions, preserving the modulus of elasticity up to $24 \mathrm{~h} \mathrm{[12].} \mathrm{In} \mathrm{another} \mathrm{study,} \mathrm{Yu} \mathrm{et} \mathrm{al.} \mathrm{[28]} \mathrm{mixed} \mathrm{polyvinylpyrrolidone} \mathrm{(PVP)} \mathrm{with} \mathrm{soybean} \mathrm{lecithin}$ to create a fibrous network by electrospinning. Formation of liposomes and vesicles with a very narrow distribution between 120-370 $\mathrm{nm}$ was observed after immersion of lecithin/PVP fibers in water. To increase the stability of electrospun lipid based systems, Zhang et al. applied a hybridization strategy to produce electrospun cholesteryl-succinyl silane (CSS) nanofibers [29].

Electrospun fibers have been used for encapsulation and controlled release of bioactives [27]. The encapsulation of curcumin within electrospun fibers using Chitosan/Phospholipids [13], polylactic acid (PLA) [30,31], polyvinyl pyrrolidone [32], blends of amaranth protein isolate/pullulan [33], and cellulose acetate [34], as well as the encapsulation of the vanillin/cyclodextrin inclusion complex (vanillin/CD-IC) within electrospun polyvinyl alcohol (PVA) [35] fibers has been reported.

This study aimed to develop electrospun phospholipid microfibers to encapsulate vanillin and curcumin as model phenolic compounds and investigate their morphology, release and antioxidant properties.

\section{Results and Discussion}

\subsection{Morphology}

Phospholipid microfibers were obtained by electrospinning using limonene and isooctane solvents, as reported previously [11,12]. The fibrous structure (Figure 1a,b) is composed of individual, uniform and randomly oriented fibers with average diameters of $15.74 \pm 4.68 \mu \mathrm{m}$ and $4.51 \pm 1.27 \mu \mathrm{m}$ for limonene and isooctane, respectively.

The higher average diameter of electrospun asolectin phospholipid using limonene as solvent in comparison with isooctane is related to the dielectric constant ( $\varepsilon$ solvent) and the evaporation point (Bp solvent) of the solvents. Limonene has a higher evaporation point and dielectric constant $\left(176{ }^{\circ} \mathrm{C}\right.$; 2.3) compared to isooctane $\left(99^{\circ} \mathrm{C}, 1.92\right)$, thus slower evaporation takes place resulting in fibers with higher average diameter as discussed in our previous studies [11].

Electrospun phospholipid fibers loaded with vanillin and curcumin were also developed with average diameters of $20.36 \pm 5.4 .5$ and $4.42 \pm 1.71 \mu \mathrm{m}$, respectively (Figure 1c,d). The inclusion of 
vanillin and curcumin on phospholipid solutions did not significantly change the morphology of electrospun phospholipid fibers, suggesting that the bioactives were efficiently encapsulated and well distributed within the microfibers. The increase in fiber diameter after encapsulation of bioactives within electropsun fibers has been well reported $[13,36]$.
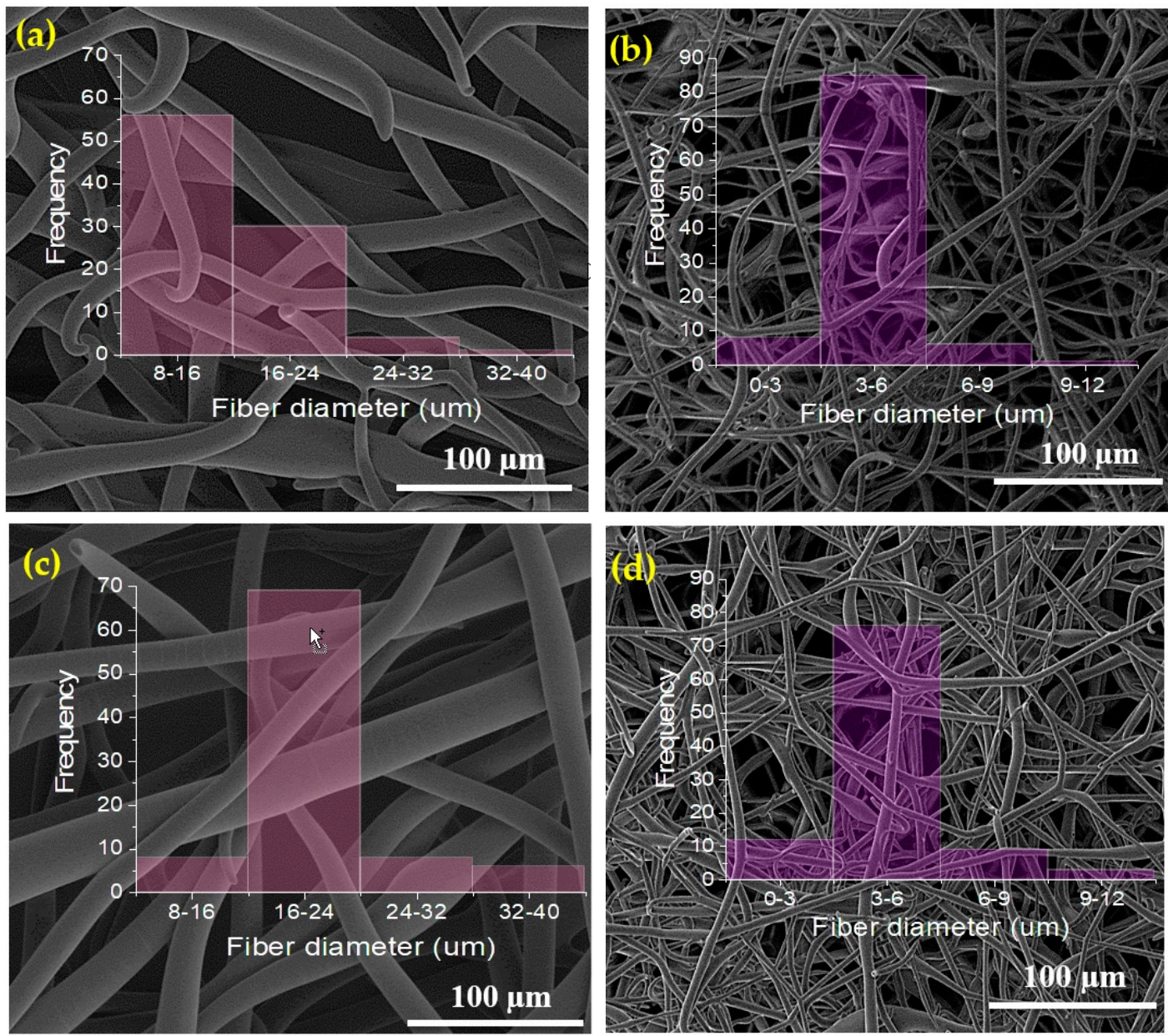

Figure 1. SEM images and corresponding histograms of the diameter distribution of electrospun phospholipid fibers prepared using limonene (a) and isooctane (b) as solvents encapsulating vanillin (c) and curcumin (d).

\subsection{FTIR Analysis}

Figure 2a,b shows the FTIR spectra of asolectin, vanillin, curcumin, asolectin electrospun fibers made with isooctane and limonene (controls) and asolectin fibers with encapsulated vanillin and curcumin, respectively. Table 1 lists the assigned peaks.

The FTIR spectrum of pure asolectin powder showed the peaks at 3000 and $2800 \mathrm{~cm}^{-1}$ corresponding to the $\mathrm{C}-\mathrm{H}$ stretching of $\mathrm{CH}_{2}$ groups, and the peaks at $1730 \mathrm{~cm}^{-1}$ and $1240 \mathrm{~cm}^{-1}$ corresponded to $\mathrm{C}=\mathrm{O}$ stretching and $\mathrm{PO}_{2}{ }^{-}$groups, respectively (Figure 2a) [37]. The features for asolectin fibers remained the same as the pure asolectin powder before the electrospinning process in both solvents, suggesting that the electrospinning process and the solvents did not change the physico-chemical properties of asolectin. 
(a)

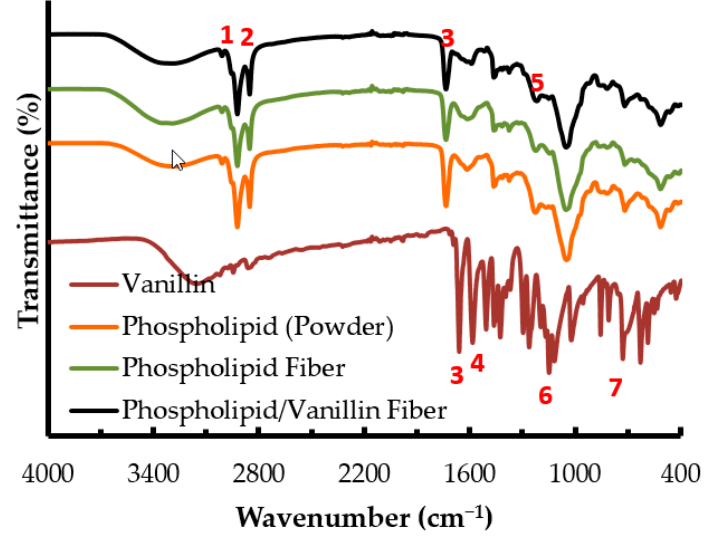

(b)

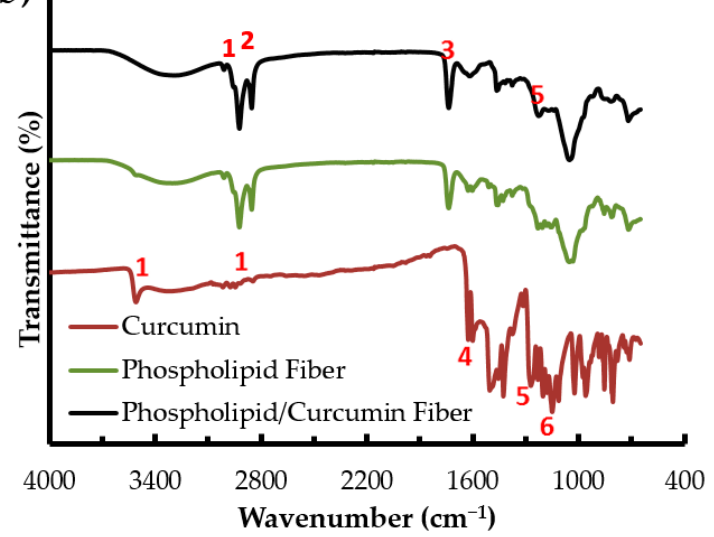

Figure 2. FTIR spectra of vanillin powder, asolectin powder, electrospun asolectin fiber and electrospun asolectin/vanillin fiber prepared using limonene (a) and curcumin powder, electrospun asolectin fiber and electrospun asolectin/curcumin fiber prepared using isooctane (b) as solvents. The red numbers in the figure are the assigned peaks listed in Table 1.

The FTIR spectrum of pure vanillin powder indicates characteristic peaks at 731, 1510 and $1590 \mathrm{~cm}^{-1}$ which correspond to the stretching vibration absorption of the benzene ring. The peak at $1660 \mathrm{~cm}^{-1}$ is attributed to the stretching vibration of $\mathrm{C}=\mathrm{O}$ of the aldehyde group [38]. Also, the peak at $1150 \mathrm{~cm}^{-1}$ shows the presence of ether groups in pure vanillin (Figure 2a) [23,39].

For curcumin, the bands observed at 3085-3552 cm $-1,1601 \mathrm{~cm}^{-1}, 1273 \mathrm{~cm}^{-1}$, and $1152 \mathrm{~cm}^{-1}$ are respectively attributed to the phenolic $\mathrm{O}-\mathrm{H}$ stretching, stretching vibrations of the benzene ring, aromatic C-O stretching and C-O-C stretching modes (Figure 2b) [24] .

The FTIR spectra of electrospun asolectin fibers loaded with both vanillin and curcumin showed the same main peaks; therefore, it is assumed that both phenolic compounds were efficiently loaded within asolectin fibers and no interactions between the bioactives and the matrix occurred.

Table 1. IR peak assignment of the electrospun phospholipid (Phos) fibers.

\begin{tabular}{|c|c|c|c|c|c|c|c|c|}
\hline \multirow{2}{*}{$\begin{array}{c}\text { Peak } \\
\text { Number }\end{array}$} & \multicolumn{7}{|c|}{ Group Frequency $\left(\mathrm{cm}^{-1}\right)$} & \multirow[t]{2}{*}{ Assignment } \\
\hline & $\begin{array}{l}\text { Vanillin } \\
\text { Powder }\end{array}$ & $\begin{array}{l}\text { Curcumin } \\
\text { Powder }\end{array}$ & $\begin{array}{l}\text { Phos } \\
\text { Powder }\end{array}$ & $\begin{array}{c}\text { Phos } \\
\text { (Limonene) } \\
\text { Fiber }\end{array}$ & $\begin{array}{l}\text { Phos } \\
\text { (Isooctane) } \\
\text { Fiber }\end{array}$ & $\begin{array}{l}\text { Phos/ } \\
\text { Vanillin } \\
\text { Fiber }\end{array}$ & $\begin{array}{l}\text { Phos/ } \\
\text { Curcumin } \\
\text { Fiber }\end{array}$ & \\
\hline 1 & - & $3085-3552$ & 3001 & 3000 & 3000 & 3000 & 3000 & $\begin{array}{l}\text { phenolic O-H } \\
\text { stretching }\end{array}$ \\
\hline 2 & - & - & $\begin{array}{l}2920 \\
2850\end{array}$ & $\begin{array}{l}2922 \\
2852\end{array}$ & $\begin{array}{l}2930 \\
2859\end{array}$ & $\begin{array}{l}2908 \\
2847\end{array}$ & $\begin{array}{l}2923 \\
2853\end{array}$ & $\begin{array}{l}\mathrm{C}-\mathrm{H} \text { stretching of } \\
\mathrm{CH}_{2} \text { groups }\end{array}$ \\
\hline 3 & 1660 & - & 1730 & 1735 & 1746 & 1725 & 1740 & $\begin{array}{l}\mathrm{C}=\mathrm{O} \text { stretching of } \\
\text { carbonyl groups }\end{array}$ \\
\hline 4 & $\begin{array}{l}1590 \\
1510\end{array}$ & 1601 & - & - & - & - & - & $\begin{array}{l}\text { stretching vibrations } \\
\text { of the benzene ring }\end{array}$ \\
\hline 5 & & 1273 & 1240 & 1230 & 1243 & 1205 & 1229 & $\begin{array}{l}\mathrm{PO}_{2}^{-} \text {groups; } \\
\text { aromatic } \mathrm{C}-\mathrm{O} \\
\text { stretching }\end{array}$ \\
\hline 6 & 1150 & 1152 & - & - & - & - & - & C-O-C stretching \\
\hline 7 & 731 & - & - & - & - & - & - & $\begin{array}{l}\text { stretching vibrations } \\
\text { of the benzene ring }\end{array}$ \\
\hline
\end{tabular}




\subsection{Encapsulation Efficiency (EE)}

The encapsulation efficiency of vanillin and curcumin within asolectin microfibers was found to be of $85.23 \pm 1.19 \%$ and $96.39 \pm 2.81 \%$, respectively. The relatively high encapsulation efficiency is related to the high solubility of vanillin and curcumin in limonene and isooctane, respectively. Consequently, the boactives could be efficiently dispersed within the fibers and well encapsulated.

The encapsulation efficiency of vanillin using electrospun almond gum/polyvinyl alcohol (PVA) composite nanofibers was reported to range from $68 \%$ to $75 \%$ for vanillin concentrations of $1 \%$ to $3 \%$ $(w / w)$ respectively [40]. The EE of vanillin loaded within microcapsules of spray dried soy protein isolate/maltodextrin was $58.3 \%$ [41].

The EE of curcumin encapsulated within cellulose acetate electrospun fibers at concentrations of $5,10,15$, and $20 \% w / v$ was reported to be of $101.9 \pm 0.8 \%, 95.6 \pm 2.5 \%, 91.4 \pm 0.4 \%$, and $90.8 \pm 0.4 \%$, respectively [34]. In another study, the EE of curcumin within liposomes was determined to range from $80.77 \pm 4.12 \%$ to $82.32 \pm 3.91 \%$ [42].

\subsection{Total Antioxidant Capacity (TAC) Assay}

Figure 3 presents the effect of storage conditions (time, temperature and pressure) on the total antioxidant capacity of the both asolectin fibers with and without phenolic compounds. TAC was measured through the formation of the phosphomolybdenum complex and the reduction of Mo (VI) to Mo (V) by the antioxidant components in the phospholipid and phospholipid/bioactive specimens [34]. Several methods are available to measure the antioxidant capacity of food and biological systems $[43,44]$. The phosphomolybdenum method is used for extensive screening of the total antioxidant capacity of samples of very different origins and composition (hydrophobic and hydrophilic) from natural sources [45]. This is a simple low-cost method [46,47] and has been utilized for the determination of the antioxidant capacity of various compounds such as vitamin E [45], quercetin [29], curcumin [48], and flavonoid fractions of Pistacia atlantica fruit [43].

Electrospun asolectin fibers produced using limonene exhibited antioxidant capacity ranging from 76 to $89 \mu \mathrm{g}$ Galic Acid Equivalent/mg of microfibers ( $\mu \mathrm{gGAE} / \mathrm{mg}$ ) for samples stored at $4{ }^{\circ} \mathrm{C}$, and from 75 to $86 \mu \mathrm{gGAE} / \mathrm{mg}$ when stored at ambient temperature (Figure 3). Similarly, the TAC determined for asolectin fibers prepared using isooctane ranged from 76 to $80 \mu \mathrm{gGAE} / \mathrm{mg}\left(4^{\circ} \mathrm{C}\right)$ and from 71 to $80 \mu \mathrm{gGAE} / \mathrm{mg}$ (ambient temperature). These data suggested that the solvent does not play a significant role in TAC of phospholipid fibers. It is noteworthy that the slight differences of the TAC values of the (control) asolectin fibers prepared using limonene or isooctane as solvents, are related to the differences of the molecular mass of the solvents that has to be considered when using this analytical method. Phospholipids are known for their antioxidant properties $[18,19,49]$ and asolectin that contains lecithin, cephalin and other phospholipids display antioxidant activity, as demonstrated previously $[16,17]$.

For pure vanillin and curcumin powders (non-encapsulated), a decrease in TAC was observed over 15 days of storage. The TAC of vanillin stored at $4{ }^{\circ} \mathrm{C}$ was decreased by 23 (low pressure) and $25 \%$ (ambient pressure) from day 1 to day 15. At ambient temperature, the TAC of vanillin stored at low pressure and ambient pressure decreased by 30\% and 26\% respectively from 1 to day 15 . After 15 days, curcumin stored at $4{ }^{\circ} \mathrm{C}$ was observed to significantly decrease its TAC to about $28 \%$ and $44 \%$ when stored at low pressure and ambient pressure, respectively. At room temperature non-encapsulated curcumin lost around 38\% (at low pressure) and 33\% (at room pressure) of its total antioxidant capacity from day 1 to day 15. Curcumin is a bioactive susceptible to oxidation [16] and its stability is known to be negatively affected by oxygen exposure $[25,26]$.

However, after encapsulation of phenolic compounds, the TAC of asolectin fibers loaded with both curcumin and vanillin was found to be constant over time (Figure 3), suggesting that the antioxidant stability of the compounds can be maintained. Moreover, an increase in TAC was observed for fibers loaded with curcumin and vanillin, suggesting an improvement of antioxidant activity due to the combination of phospholipids with phenolic compounds. This is in accordance with previous studies 
where an improvement of TAC was confirmed by synergistic interactions of lecithins with other phenolic compounds such as tocopherols [17,50].

Previous studies showed that encapsulated curcumin could retain higher antioxidant stability in lecithin (antioxidant) stabilized emulsions compared to curcumin in Tween 20 (non-antioxidant) stabilized emulsions. The higher antioxidant activity of emulsifier could significantly lower the rate of radical permeation and consequently reduce the rate of oxidation of the encapsulated curcumin [16]. Figure 3 shows the TAC of curcumin/asolectin and curcumin/vanillin fibers over 15 days. The TAC assay was also conducted for 45 days and no evidence of reduction of TAC was observed (data not shown), suggesting that the phospholipids fibers and phospholipids/phenolic compounds fibers preserve their antioxidant activity for extended periods of time.

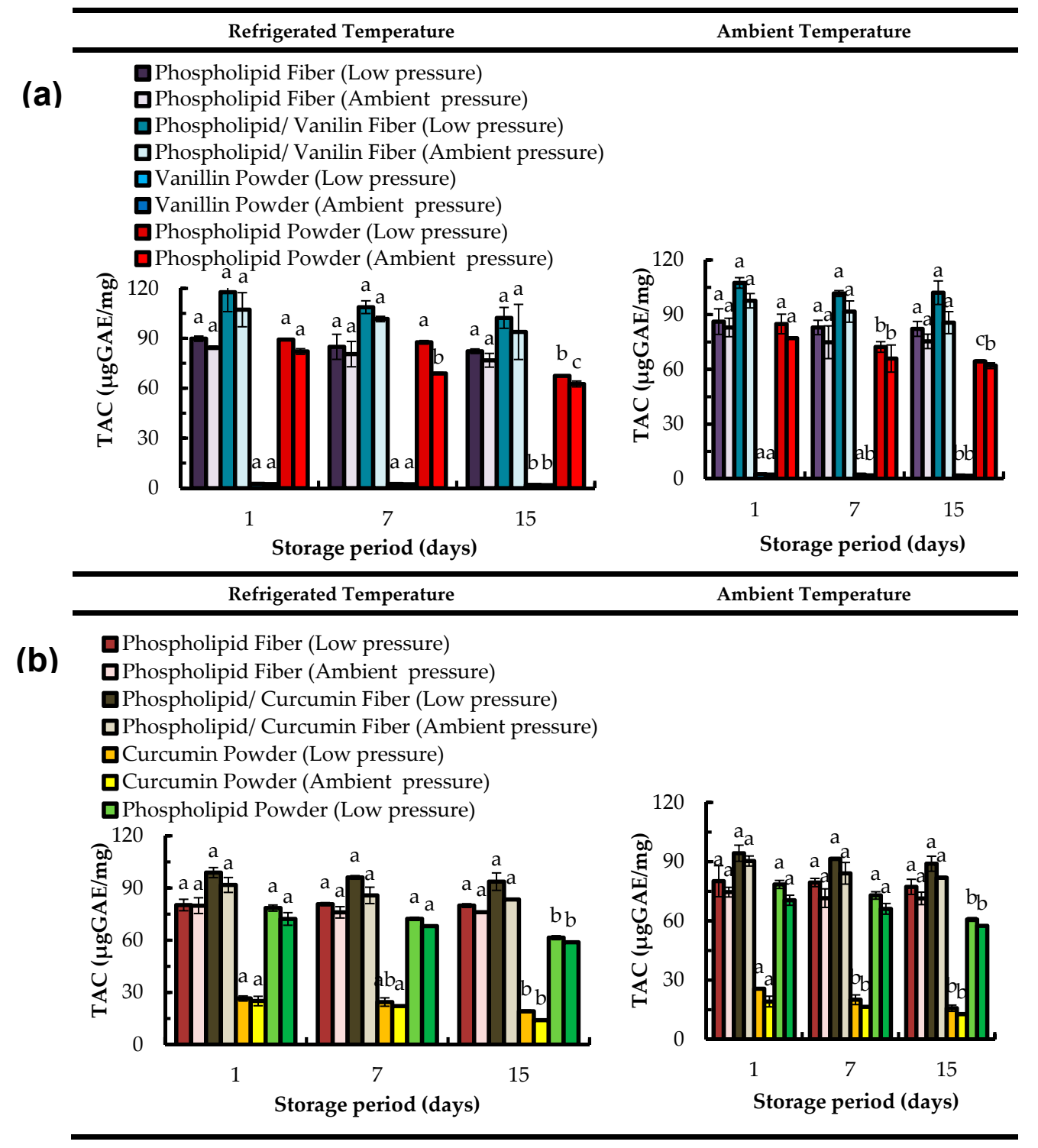

Figure 3. Total antioxidant capacity (TAC) over time of electropsun phospholipid fibers prepared using limonene (top graphs (a)) and isooctane (bottom graphs (b)) as solvent; Data are represented as mean $\pm \mathrm{SD}$ [N = 3]; a-c: significant difference at $p \leq 0.05$ in terms of total antioxidant capacity of each storage condition during storage time.

Antioxidant activity of phenolic compounds is known to be affected by the presence of oxygen and temperature. Figure 3 shows that no significant differences were observed for the TAC when 
microfibers-bioactives were stored at different temperatures (refrigerated, ambient) and pressures (vacuum, ambient pressure). However, the most favorable storage conditions for both curcumin and vanillin loaded in electrospun asolectin fibers were refrigerated temperature and low pressure, as slightly higher TAC values were determined.

The total phenolic content (TPC) within the fibers over time was also determined based on the electron transfer from phospholipid and phospholipid/bioactive specimens to the complexed Mo (IV) present in the Folin-Ciocalteu reagent [51,52] (Figure 4). Similar to TAC (Figure 3), the total phenolic content was not changed significantly over time for the phenolics encapsulated within electropsun phospholipid fibers. However, for the non-encapsulated curcumin, a reduction of TPC by $40 \%$ from day 1 to day 15 was determined when this bioactive was stored in ambient pressure and refrigerated temperature $(11.9 \mu \mathrm{gGAE} / \mathrm{mg})$. The encapsulated curcumin displayed a TPC of $24.5 \mu \mathrm{gGAE} / \mathrm{mg}$ for the same storage conditions.
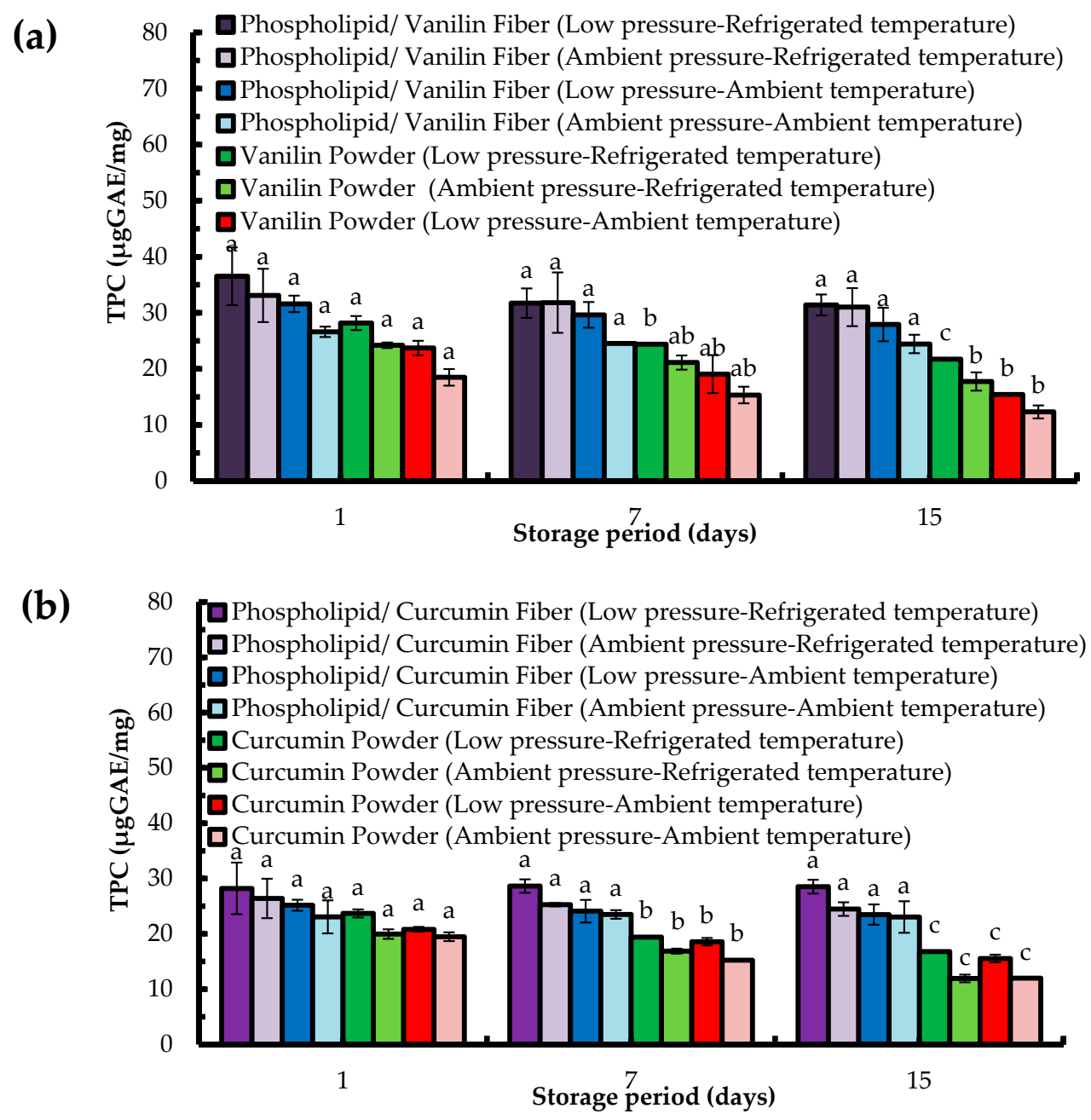

Figure 4. Total phenolic content (TPC) over time of electropsun phospholipid fibers prepared using limonene (a) and isooctan (b) as solvents; Data are represented as mean $\pm \mathrm{SD}[\mathrm{N}=3$ ]; a-c: significant difference at $p \leq 0.05$ in terms of total phenolic content of each storage condition during storage time.

The TPC of non-encapsulated vanillin was observed to decrease by about $35 \%$ when this compound was stored at reduced pressure and room temperature, reaching the values of $15 \mu \mathrm{gGAE} / \mathrm{mg}$ after 15 days. The encapsulated vanillin stored at reduced pressure and room temperature exhibited a TPC of $28 \mu \mathrm{gGAE} / \mathrm{mg}$ (Figure 4). 
Hence, TAC and TPC data demonstrate the potential of asolectin fibers to be used as antioxidant systems as well as efficient matrices for the encapsulation of phenolic compounds. Cases of preservation of TPC within electropsun fibers have been reported [53-55].

\subsection{Stability of Phenolic Compounds Test under Storage by ${ }^{1} H-N M R$}

The composition of the electrospun asolectin fibers with encapsulated curcumin or vanillin was analyzed using ${ }^{1} \mathrm{H}-\mathrm{NMR}$ spectroscopy. The chemical stability of vanillin and curcumin and the retention of these encapsulated phenolic compounds in the fibers upon storage were monitored. ${ }^{1} \mathrm{H}-\mathrm{NMR}$ spectra of the fibers in DMSO- $d_{6}$ solution were obtained after increasing storage times at room temperature ranging from 1 day to 30 days (Figure 5). Figure $5 a(i), b(i)$ shows the assigned ${ }^{1} \mathrm{H}-\mathrm{NMR}$ spectra of vanillin and curcumin as references. Figure $5 \mathrm{a}(\mathrm{ii}), \mathrm{b}(\mathrm{ii})$ shows the spectra for each fiber after 1 day of storage. In the region $0.5-3 \mathrm{ppm}$, several peaks corresponding to the aliphatic tails of the phospholipids can be seen. Highlighted in red are the peaks corresponding to the phenolic compounds. After 30 days of storage (Figure 5a(iii),b(iii)), the spectra have not altered. This suggests that not only are the encapsulated curcumin and vanillin chemically stable over the 30 days storage time, but the concentration of encapsulated phenolic compounds does not decrease under the storage conditions. This finding is in agreement with the total phenolic content data (TPC) measured at room temperature and pressure (Figure 3), suggesting that asolectin fibers were effective matrices to prolong the stability of vanillin and curcumin.

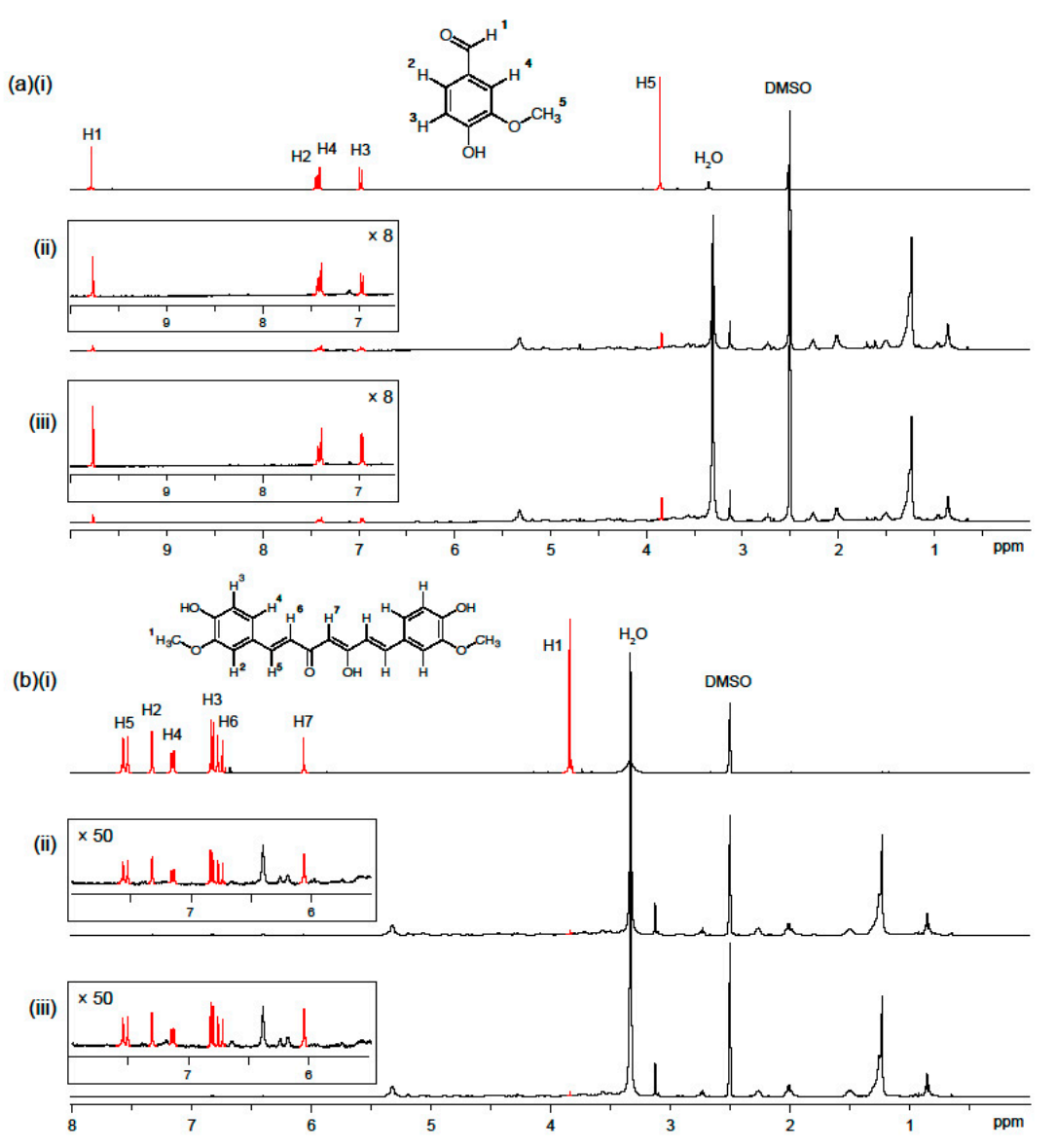

Figure 5. ${ }^{1} \mathrm{H}-\mathrm{NMR}$ spectra $(298 \mathrm{~K}, 400 \mathrm{MHz})$ in DMSO- $d_{6}$ of vanillin (a(i)) and curcumin (b(i)); and electrospun phospholipid fibers with encapsulated vanillin and curcumin analyzed at different storage times: (ii) 1 day and (iii) 30 days. 


\subsection{In Vitro Release Study}

The release profiles at $37^{\circ} \mathrm{C}$ of vanillin and curcumin from asolectin microfibers are shown in Figure 6. For both vanillin and curcumin, a steady increase in the release of the bioactives was observed up to $240 \mathrm{~min}$. At this time, the released amount of vanillin was $95 \%$ while the released amount of curcumin was $70 \%$. From 240 to $300 \mathrm{~min}$, only a slight increase of the released bioactives was observed.

The lower percentage of released curcumin compared to vanillin could be attributed to its hydrophobic nature. Similar curcumin release profiles showing a steady increase of curcumin released from electrospun nanofibers, produced using chitosan/phospholipid [13], blends of amaranth protein isolate (API)/pullulan [33] and PLGA copolymer solutions [56] have been reported. On the other hand, a higher percentage of release (near 100\%) of vanillin from almond gum/polyvinyl alcohol (PVA) electrospun fibers has been observed in aqueous media, due to the higher solubility and higher swelling degree of almond gum/PVA/vanillin nanofiber in distilled water [40].

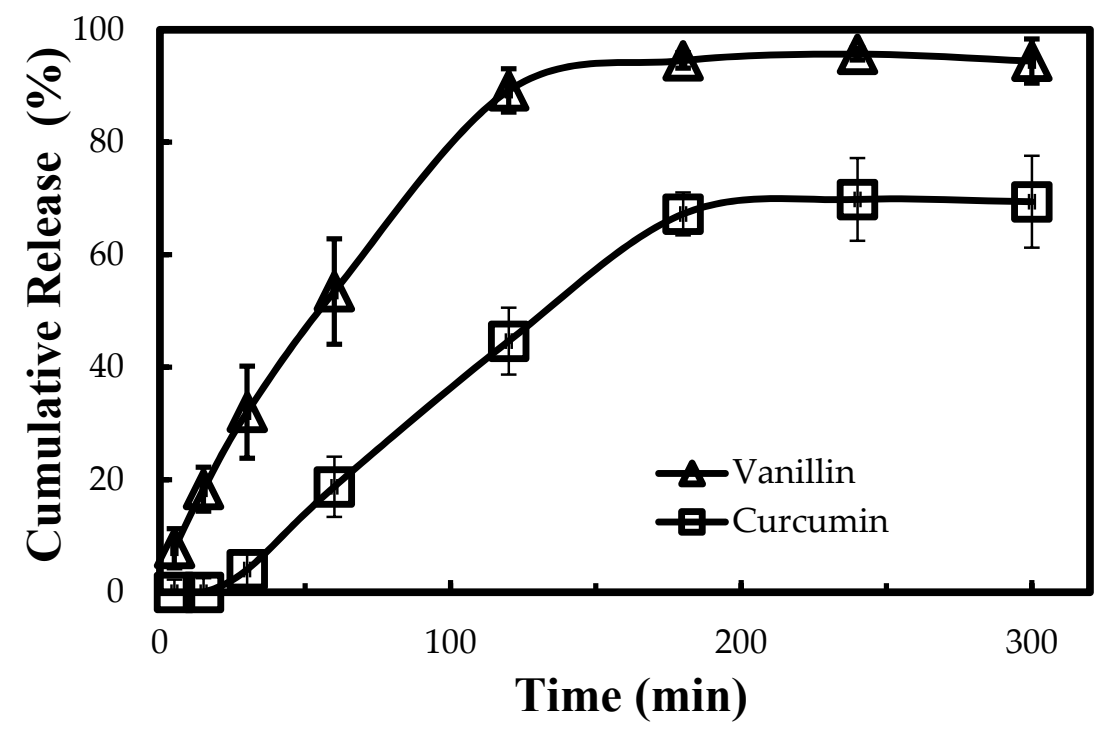

Figure 6. Cumulative release of vanillin and curcumin from phospholipid fibers into phosphate buffered saline (PBS), $\mathrm{pH}=7.6(\mathrm{n}=3)$. The error bars in the figure represent the standard deviation (SD).

The release mechanism of the phenolic compounds from electrospun asolectin fibers was analyzed using the Korsmeyer-Peppas model [57]. This model concerns the release of drugs from cylindrical structures and predicts whether the release of the compound from a matrix follows Fickian diffusion, through determination of the coefficient " $n$ " estimated from linear regression of the $\log$ (Cumulative Release) as a function of $\log$ (Time). The " $\mathrm{n}$ " determined from both release curves was above 0.45 , with a correlation value $\left(R^{2}\right)$ of 0.98 and 0.99 for vanillin and curcumin respectively, suggesting that the release mechanism of both bioactives was mainly due to the swelling of the phospholipid fibers that influenced the release of bioactives. Wongsasulak and co-authors [58] also reported that the swelling of the matrix (electrospun polymers of zein, poly(ethylene oxide), and chitosan) triggered the release of the bioactive ( $\alpha$-tocopherol) according to Korsmeyer-Peppas model. To confirm the changes in morphology of phospholipid fibers after immersion in PBS, Environmental SEM (ESEM) photographs were taken at different time points of immersion (Figure 7). After one hour in PBS, fibers were observed to slightly increase their diameter as a result of the swelling of the matrix. At the end of $2 \mathrm{~h}$, the progressive water absorption was observed (Figure 7c) resulting in the loss of fibril-like shape, that was further observed at the end of 4 hours of immersion in PBS (Figure 7d). It is to be noted that a previous study suggested that electrospun phospholipid scaffolds, made from lethicin solutions, lack physical stability as a consequence of hydration and further breakdown of fibril-like structures in the presence of moisture [59]. 

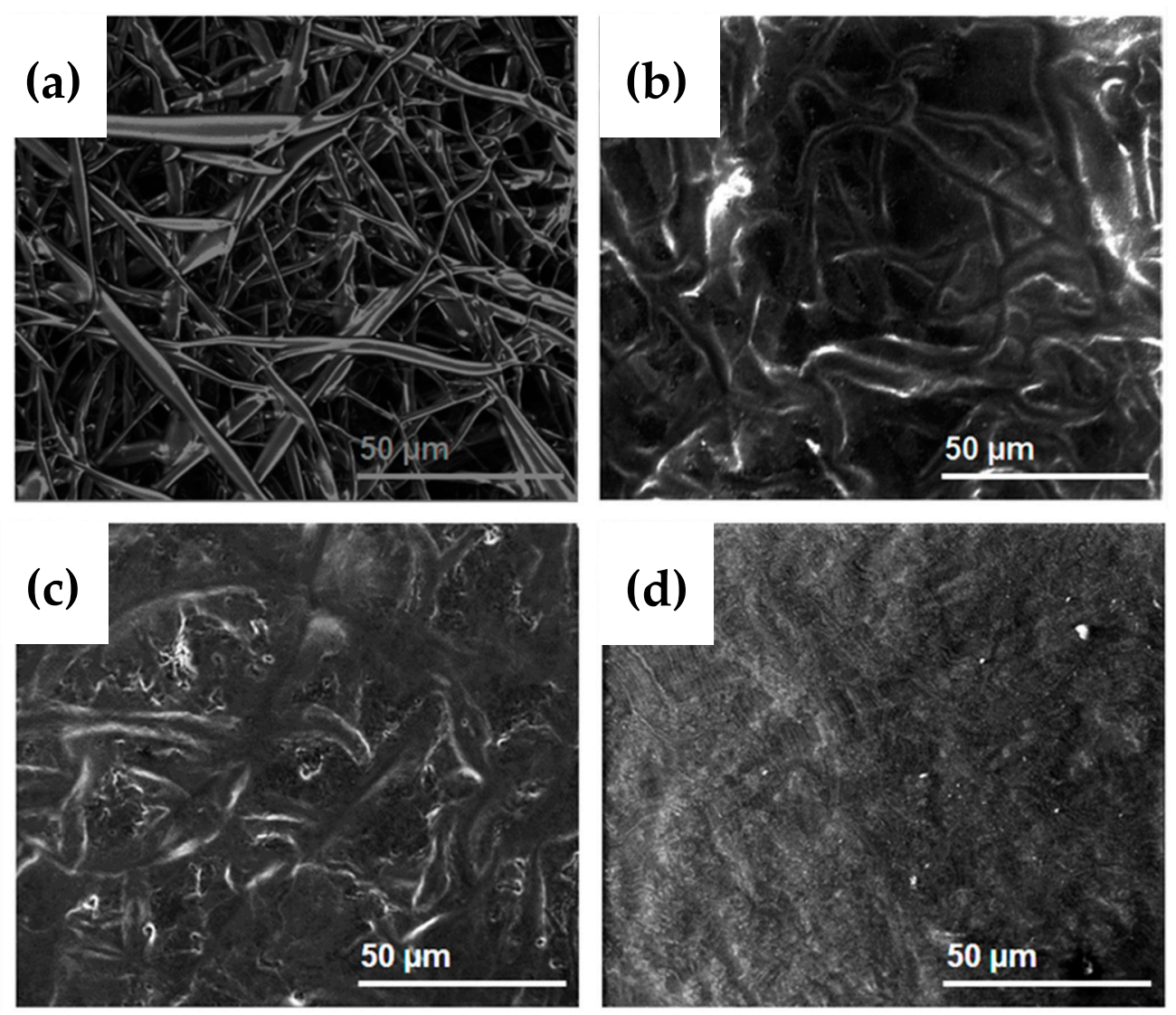

Figure 7. Environmental SEM (ESEM) images of elestrospun asolectin microfiber fibers (a); showing its morphology after immersion in PBS for $1 \mathrm{~h} \mathrm{(b)} ; 2 \mathrm{~h} \mathrm{(c)} \mathrm{and} 4 \mathrm{~h} \mathrm{(d).}$

$\mathrm{Yu}$ and co-authors reported the fabrication of electropsun composite fibers made of polyvinylpyrrolidone (PVP) and soybean lecithin [27] and observed the collapse of composite fibers after contact with water within less than one minute as a result of changes in the hydrophilic/hydrophobic nature. Our system was observed to last longer which allowed the sustained release of encapsulated bioactives for $360 \mathrm{~min}$ (Figure 6).

\section{Materials and Methods}

\subsection{Materials}

Asolectin from soybean (Sigma-Aldrich product nr: 11145, lot nr: BCB66221V) was used as received. It contains approximately lecithin (25-33\%), cephalin and phosphatidylinositol, saturated fatty acids $(24 \%)$, mono-unsaturated $(14 \%)$ and poly-unsaturated fatty acids $(62 \%)$. Methyl-4(1-methylethenyl)-cyclohexene (limonene), isooctane, curcumin and vanillin were obtained from Sigma-Aldrich and used as received without further purification.

\subsection{Preparation of Electrospinning Solutions}

A total of $60 \%(w t / w t)$ asolectin phospholipid was dissolved in limonene and isooctane at room temperature and then, vanillin $(3 \%, w t / v)$ or curcumin $(0.5 \% w t / v)$ were added, respectively, and stirred for $15 \mathrm{~min}$ before electrospinning processing. Solutions of $60 \%(w t / w t)$ asolectin were also prepared in both limonene and isooctane without phenolic compounds. Isooctane and Limonene were selected as solvents due to their capability produce electrospun phospholipid fibers [11] and to dissolve curcumin and vanillin, respectively. 


\subsection{Electrospinning Processing}

The electrospinning setup included a high voltage generator (ES50P-10W, Gamma High Voltage Research, Inc., Ormond Beach, FL, USA) to provide a voltage of $21 \mathrm{kV}$, and syringe pump (New Era Pump Systems, Inc., Farmingdale, NJ, USA) to feed the solutions at a flow rate of $0.01 \mathrm{~mL} / \mathrm{min}$. Phospholipids fibers were collected on a steel plate covered with aluminium foil placed at a distance of $10 \mathrm{~cm}$ from the end of the needle. A blunt end stainless steel needle (Proto Advantage, Ancaster, ON, Canada) with inner diameters between $0.8 \mathrm{~mm}$ to $0.4 \mathrm{~mm}$ was used. The electrospinning process was carried out at ambient conditions.

\subsection{Morphology}

The morphology of the electrospun phospholipid, phospholipid/vanillin and phospholipid/ curcumin fibers was investigated using a Quanta FEG 3D scanning electron microscope (SEM). Samples were attached on metal stubs with double-sided adhesive carbon tape and coated with $6 \mathrm{~nm}$ of gold for better conductivity using a sputter coater (Leica Coater ACE 200). The average fiber diameter was calculated using image J analysis software (National Institutes of Health, MD, USA) measured at 100 different points for each image. Changes in morphology of electrospun phospholipid fibers were further monitored after contact in PBS by Environmental SEM (ESEM). Samples were mounted on aluminium stubs and placed upside down immersed in PBS for 1, 2 and $4 \mathrm{~h}$ prior to the visualization in the Quanta FEG 3D SEM.

\subsection{Fourier Transform Infrared (FTIR) Spectroscopy}

FTIR spectra in the transmission mode were recorded using a Perkin 124 Elmer Spectrum 100 spectrometer based on a Universal Attenuated Total Reflectance sensor 125 (UATR-FTIR). The infrared peaks were identified using Spectrum ${ }^{\mathrm{TM}} 10$ software using $1 \% \mathrm{~T}$ peak threshold. Spectra were plotted as percentage transmittance $(\% \mathrm{~T})$ against wavenumber $\left(\mathrm{cm}^{-1}\right)$.

\subsection{Encapsulation Efficiency}

The encapsulation efficiency of the phenolic compounds (vanillin and curcumin) in asolectin fibers was determined by extracting the bioactives from the fibers using water and ethanol in a sonication bath for $30 \mathrm{~min}$ prior to centrifugation at $4500 \mathrm{rpm}$ for $15 \mathrm{~min}$. The concentration of bioactives in the supernatant was determined using a UV-Vis spectrophotometer (U-1500, Hitachi, Tokyo, Japan), where absorbance of vanillin and curcumin were measured at wavelengths of $280 \mathrm{~nm}$ and $425 \mathrm{~nm}$, respectively. Standard curves for vanillin and curcumin were prepared with concentrations ranging from $0-100 \mu \mathrm{g} / \mathrm{mL}$. Encapsulation efficiency was calculated using the following Equation (1):

$$
\% \text { EncapsulationEfficiency }=\frac{\text { Phenolic compounds }(\text { encapsulated })}{\text { Phenolic compounds }(\text { total })} \times 100
$$

\subsection{Total Antioxidant Capacity Assay (TAC)}

Antioxidant capacities of phospholipid powder, vanillin powder, curcumin powder, phospholipid fibers, phospholipid/vanillin fibers and phospholipid/curcumin fibers were evaluated by the method of Jayaprakasha et al., 2006 [48]. Asolectin fibers (with and without phenolic compounds) were stored at different pressures (ambient and vacuum) and temperatures (refrigerated $4{ }^{\circ} \mathrm{C}$ and room temperature) and their TAC was evaluated after 1, 7 and 15 days storage. An amount of $300 \mu \mathrm{L}$ of diluted extracted solution prepared in methanol was added to an Eppendorf tube containing $3 \mathrm{~mL}$ reagent solution ( $0.6 \mathrm{M}$ sulfuric acid, $28 \mathrm{mM}$ sodium phosphate and $4 \mathrm{mM}$ ammonium molybdate). The Eppendorf tubes were capped and incubated in a water bath at $95{ }^{\circ} \mathrm{C}$ for $90 \mathrm{~min}$. Then, samples were cooled to room temperature and the absorbance of each sample was measured at $695 \mathrm{~nm}$ against 
a blank ( $1 \mathrm{~mL}$ of reagent solution and the appropriate volume of the same solvent used for the sample). Gallic acid was used as the reference.

\subsection{Total Phenolic Content (TPC)}

The total phenolic content of the stored samples at different pressures (ambient and vacuum) and temperatures (refrigerated at $4{ }^{\circ} \mathrm{C}$ and room temperature) were determined via a modified Folin-Ciocalteu method [51] for 1, 7, 15 and 45 days of their storage. Briefly, $0.3 \mathrm{~mL}$ of diluted extract solution $(5 \mathrm{mg} / \mathrm{mL})$ was mixed with $0.6 \mathrm{~mL}$ of deionized water and $0.5 \mathrm{~mL}$ of Folin-Ciocalteu reagent in a test tube and then $1.5 \mathrm{~mL}$ of $20 \%$ sodium carbonate aqueous solution was added and the volume was made up to $10 \mathrm{~mL}$ with deionized water. The samples were incubated for $30 \mathrm{~min}$ at room temperature in darkness and then absorbance measured at $760 \mathrm{~nm}$ using and UV-Vis spectrophotometer (U-1500, Hitachi, Tokyo, Japan). The determination of the phenolic content was obtained by using gallic acid as a standard.

\subsection{Stability of Phenolic Compounds Test under Storage by ${ }^{1} H-N M R$ Spectroscopy}

Asolectin, asolectin/vanillin and asolectin/curcumin fibers were stored in ambient conditions at room temperature in the laboratory for 30 days. After 1, 15 and 30 days of storage, small samples of fibers were analyzed by ${ }^{1} \mathrm{H}-\mathrm{NMR}$ spectroscopy $(400 \mathrm{MHz}$ NMR spectrometer, Bruker, Billerica, MA, USA) at $298 \mathrm{~K}$ in order to compare the amount of the remaining phenolic compounds in the samples during storage time. Samples for ${ }^{1} \mathrm{H}-\mathrm{NMR}$ spectroscopic analysis were prepared in DMSO- $d_{6}$ at a concentration of $10 \mathrm{mg} / \mathrm{mL}$. The samples were alternatively sonicated and heated in closed vials with a heat gun in order to dissolve the material. ${ }^{1} \mathrm{H}-\mathrm{NMR}$ spectra of vanillin and curcumin were recorded as references.

\subsection{In Vitro Release Study}

The in vitro release of phenolic compounds from asolectin fibers was determined by UV-Vis spectroscopy [13]. Briefly, asolectin fibers (15 mg) were included in dialysis bags (SpectraLab with a MWCO 6-8 kDa) that were further sealed and placed into $20 \mathrm{~mL}$ phosphate buffer saline (pH 7.4) in a test tube in a shaking water bath at $37^{\circ} \mathrm{C}$ for $360 \mathrm{~min}$. The $2-\mathrm{mL}$ samples were collected at each interval time point and replaced by fresh media (PBS, $2 \mathrm{~mL}$ ). The amount of phenolic compounds released in the supernatant was determined afterwards using a UV-Vis spectrophotometer (U-1500, Hitachi, Tokyo, Japan) at optical wavelengths of 280 and 425 for vanillin and curcumin, respectively. A calibration curve of phenolic compounds in phosphate buffer saline ( $\mathrm{pH} 7.4$ ) was constructed with a concentration range from $0-100 \mu \mathrm{g} / \mathrm{mL}$. The experiments were performed in triplicate and the results were reported as average values \pm standard deviation.

The mechanism of release was investigated following the Korsmeyer-Peppas model:

$$
\frac{\mathrm{Mt}}{\mathrm{M} \infty}=\mathrm{kt}^{\mathrm{n}}
$$

where $\mathrm{Mt} / \mathrm{M} \infty$ is the fraction of drug released at time $\mathrm{t}, \mathrm{k}$ is the rate constant and $\mathrm{n}$ is the release exponent. If $\mathrm{n} \leq 0.45$, the release mechanism follows a Fickian diffusion and for $0.45<\mathrm{n}<0.89$ the drug release follows a non-Fickian diffusion (anomalous transport) [35].

\subsection{Statistical Analysis}

Presented results are an average of at least three independent experiments and are presented as mean \pm standard deviation. The results were analyzed with one-way ANOVA using Fisher's test in Minitab software version 16 (Minitab Inc., State College, PA, USA). The significant differences between samples were considered at a significance level of $p \leq 0.05$. 


\section{Conclusions}

In this study, electrospun phospholipid (asolectin) microfibers were investigated as encapsulation and antioxidant matrices for phenolic compounds, such as vanillin and curcumin. Asolectin fibers were observed to have antioxidant properties. Such antioxidant properties were improved after the encapsulation of the phenolic compounds, as observed from TAC and TPC assays. The antioxidant capacity of curcumin/phospholipid and vanillin/phospholipid microfibers was observed to remain stable over time at different temperatures (refrigerated, ambient) and pressures (vacuum, ambient), while the pristine non-encapsulated phenolic compounds decreased their TAC and TPC values. Moreover, the phospholipid matrix permitted the release of both curcumin and vanillin upon aqueous emersion, mainly due to the swelling of the phospholipid fibers that triggered the diffusion of bioactives. The above studies confirm the efficacy of electrospun phospholipid microfibers as encapsulation and antioxidant systems.

Acknowledgments: The authors are grateful to Hamed Safafar for fruitful discussions about antioxidant capacity of phospholipid fibers.

Author Contributions: A.C.M. and I.S.C. conceived and designed the experiments; E.S., A.C.M., V.B., S.R.B. performed the experiments; E.S., A.C.M., V.B., S.R.B., I.S.C. analyzed the data and wrote the manuscript.

Conflicts of Interest: The authors declare no conflict of interest.

\section{References}

1. Gosangari, S.L.; Watkin, K.L. Effect of preparation techniques on the properties of curcumin liposomes: Characterization of size, release and cytotoxicity on a squamous oral carcinoma cell line. Pharm. Dev. Technol. 2012, 17, 103-109. [CrossRef] [PubMed]

2. Maria, A.; Maria, B.; Sinico, C.; Sapienza, L.; Moro, P.A. Phospholipid-detergent systems: Effects of polysorbates on the release of liposomal caffeine. Farmaco 1998, 53, 650-654.

3. Shazly, G.; Nawroth, T.; Langguth, P. Comparison of dialysis and dispersion methods for in vitro release determination of drugs from multilamellar liposomes. Dissolut. Technol. 2008, 15, 7-10. [CrossRef]

4. Hühn, E.; Buchholz, H.-G.; Shazly, G.; Maus, S.; Thews, O.; Bausbacher, N.; Rösch, F.; Schreckenberger, M.; Langguth, P. Predicting the in vivo release from a liposomal formulation by IVIVC and non-invasive positron emission tomography imaging. Eur. J. Pharm. Sci. 2010, 41, 71-77. [CrossRef] [PubMed]

5. Huynh, N.T.; Passirani, C.; Saulnier, P.; Benoit, J.P. Lipid nanocapsules: A new platform for nanomedicine. Int. J. Pharm. 2009, 379, 201-209. [CrossRef] [PubMed]

6. Mendes, A.C.; Baran, E.T.; Reis, R.L.; Azevedo, H.S. Fabrication of phospholipid-xanthan microcapsules by combining microfluidics with self-assembly. Acta Biomater. 2013, 9, 6675-6685. [CrossRef] [PubMed]

7. Taylor, T.M.; Weiss, J.; Davidson, P.M.; Bruce, B.D. Liposomal nanocapsules in food science and agriculture. Crit. Rev. Food Sci. Nutr. 2005, 45, 587-605. [CrossRef] [PubMed]

8. Mouritsen, O.G. Life-As A Matter of Fat: The Emerging Science of Lipidomics; Springer: Heidelberg, Germany, 2005; ISBN 3540232486.

9. Mouritsen, O.G. Lipids, curvature, and nano-medicine. Eur. J. Lipid Sci. Technol. 2011, 113, $1174-1187$. [CrossRef] [PubMed]

10. McKee, M.G.; Layman, J.M.; Cashion, M.P.; Long, T.E. Phospholipid nonwoven electrospun membranes. Science 2006, 311, 353-355. [CrossRef] [PubMed]

11. Jørgensen, L.; Qvortrup, K.; Chronakis, I.S. Phospholipid electrospun nanofibers: Effect of solvents and co-axial processing on morphology and fiber diameter. RSC Adv. 2015, 5, 53644-53652. [CrossRef]

12. Mendes, A.C.; Nikogeorgos, N.; Lee, S.; Chronakis, I.S. Nanomechanics of Electrospun Phospholipid Fiber. Appl. Phys. Lett. 2015, 106. [CrossRef]

13. Mendes, A.C.; Gorzelanny, C.; Halter, N.; Schneider, S.W.; Chronakis, I.S. Hybrid electrospun chitosan-phospholipids nanofibers for transdermal drug delivery. Int. J. Pharm. 2016, 510, 48-56. [CrossRef] [PubMed] 
14. Mendes, A.C.; Shekarforoush, E.; Engwer, C.; Beeren, S.R.; Gorzelanny, C.; Goycoolea, F.M.; Chronakis, I.S. Co-assembly of chitosan and phospholipids into hybrid hydrogels. Pure Appl. Chem. 2016, 88, 905-916. [CrossRef]

15. De Sousa, R.S.; de Moraes Nogueira, A.O.; Marques, V.G.; Clementin, R.M.; de Lima, V.R. Effects of $\alpha$-eleostearic acid on asolectin liposomes dynamics: Relevance to its antioxidant activity. Bioorg. Chem. 2013, 51, 8-15. [CrossRef] [PubMed]

16. Pan, Y.; Tikekar, R.V.; Nitin, N. Effect of antioxidant properties of lecithin emulsifier on oxidative stability of encapsulated bioactive compounds. Int. J. Pharm. 2013, 450, 129-137. [CrossRef] [PubMed]

17. Judde, A.; Villeneuve, P.; Rossignol-Castera, A.; Guillou, A. Antioxidant effect of soy lecithins on vegetable oil stability and their synergism with tocopherols. J. Am. Oil Chem. Soc. 2003, 80, 1209-1215. [CrossRef]

18. Cui, L.; Decker, E.A. Phospholipids in foods: Prooxidants or antioxidants? J. Sci. Food Agric. 2016, 96, 18-31. [CrossRef] [PubMed]

19. Choe, E.; Min, D.B. Mechanisms of Antioxidants in the Oxidation of Foods. Compr. Rev. Food Sci. Food Saf. 2009, 8, 345-358. [CrossRef]

20. Doert, M.; Jaworska, K.; Moersel, J.T.; Kroh, L.W. Synergistic effect of lecithins for tocopherols: Lecithin-based regeneration of $\alpha$-tocopherol. Eur. Food Res. Technol. 2012, 235, 915-928. [CrossRef]

21. Brewer, M.S. Natural Antioxidants: Sources, Compounds, Mechanisms of Action, and Potential Applications. Compr. Rev. Food Sci. Food Saf. 2011, 10, 221-247. [CrossRef]

22. Celebioglu, A.; Kayaci-Senirmak, F.; Kusku, S.I.; Durgun, E.; Uyar, T. Polymer-free nanofibers from vanillin/cyclodextrin inclusion complexes: High thermal stability, enhanced solubility and antioxidant property. Food Funct. 2016. [CrossRef] [PubMed]

23. Hundre, S.Y.; Karthik, P.; Anandharamakrishnan, C. Effect of whey protein isolate and $\beta$-cyclodextrin wall systems on stability of microencapsulated vanillin by spray-freeze drying method. Food Chem. 2015, 174, 16-24. [CrossRef] [PubMed]

24. Sun, X.Z.; Williams, G.R.; Hou, X.X.; Zhu, L.M. Electrospun curcumin-loaded fibers with potential biomedical applications. Carbohydr. Polym. 2013, 94, 147-153. [CrossRef] [PubMed]

25. Kharat, M.; Du, Z.; Zhang, G.; McClements, D.J. Physical and chemical stability of curcumin in aqueous solutions and emulsions: Impact of $\mathrm{pH}$, temperature, and molecular environment. J. Agric. Food Chem. 2017. [CrossRef] [PubMed]

26. Price, L.C.; Buescher, R.W. Decomposition of turmeric curcuminoids as affected by light, solvent and oxygen. J. Food Biochem. 1996, 20, 125-133. [CrossRef]

27. Mendes, A.C.; Stephansen, K.; Chronakis, I.S. Electrospinning of food proteins and polysaccharides. Food Hydrocoll. 2017, 68, 53-68. [CrossRef]

28. Yu, D.-G.; Branford-White, C.; Williams, G.R.; Bligh, S.W.A.; White, K.; Zhu, L.-M.; Chatterton, N.P. Self-assembled liposomes from amphiphilic electrospun nanofibers. Soft Matter 2011, 7, 8239. [CrossRef]

29. Zhang, J.; Cohn, C.; Qiu, W.; Zha, Z.; Dai, Z.; Wu, X. Atomic force microscopy of electrospun organic-inorganic lipid nanofibers. Appl. Phys. Lett. 2011, 99, 103702. [CrossRef] [PubMed]

30. Mai, T.T.T.; Nguyen, T.T.T.; Le, Q.D.; Nguyen, T.N.; Ba, T.C.; Nguyen, H.B.; Phan, T.B.H.; Tran, D.L.; Nguyen, X.P.; Park, J.S. A novel nanofiber Cur-loaded polylactic acid constructed by electrospinning. Adv. Nat. Sci. Nanosci. Nanotechnol. 2012, 3, 25014. [CrossRef]

31. Dhurai, B.; Saraswathy, N.; Maheswaran, R.; Sethupathi, P.; Vanitha, P.; Vigneshwaran, S.; Rameshbabu, V. Electrospinning of curcumin loaded chitosan/poly (lactic acid) nanofilm and evaluation of its medicinal characteristics. Front. Mater. Sci. 2013, 7, 350-361. [CrossRef]

32. Wang, C.; Ma, C.; Wu, Z.; Liang, H.; Yan, P.; Song, J.; Ma, N.; Zhao, Q. Enhanced Bioavailability and Anticancer Effect of Curcumin-Loaded Electrospun Nanofiber: In Vitro and In Vivo Study. Nanoscale Res. Lett. 2015, 10, 439. [CrossRef] [PubMed]

33. Blanco-Padilla, A.; Lopez-Rubio, A.; Loarca-Pina, G.; Gomez-Mascaraque, L.G.; Mendoza, S. Characterization, release and antioxidant activity of curcumin-loaded amaranth-pullulan electrospun fibers. LWT Food Sci. Technol. 2015, 63, 1137-1144. [CrossRef]

34. Suwantong, O.; Opanasopit, P.; Ruktanonchai, U.; Supaphol, P. Electrospun cellulose acetate fiber mats containing curcumin and release characteristic of the herbal substance. Polymer 2007, 48, 7546-7557. [CrossRef] 
35. Kayaci, F.; Uyar, T. Encapsulation of vanillin/cyclodextrin inclusion complex in electrospun polyvinyl alcohol (PVA) nanowebs: Prolonged shelf-life and high temperature stability of vanillin. Food Chem. 2012, 133, 641-649. [CrossRef]

36. Kanawung, K.; Panitchanapan, K.; Puangmalee, S.; Utok, W.; Kreua-ongarjnukool, N.; Rangkupan, R.; Meechaisue, C.; Supaphol, P. Preparation and Characterization of Polycaprolactone/Diclofenac Sodium and Poly(vinyl alcohol)/Tetracycline Hydrochloride Fiber Mats and Their Release of the Model Drugs. Polym. J. 2007, 39, 369-378. [CrossRef]

37. Lopes De Azambuja, C.R.; Dos Santos, L.G.; Rodrigues, M.R.; Rodrigues, R.F.M.; Da Silveira, E.F.; Azambuja, J.H.; Flores, A.F.C.; Horn, A.P.; Dora, C.L.; Muccillo-Baisch, A.L.; et al. Physico-chemical characterization of asolectin-genistein liposomal system: An approach to analyze its in vitro antioxidant potential and effect in glioma cells viability. Chem. Phys. Lipids 2015, 193, 24-35. [CrossRef] [PubMed]

38. Peng, H.; Xiong, H.; Li, J.; Xie, M.; Liu, Y.; Bai, C.; Chen, L. Vanillin cross-linked chitosan microspheres for controlled release of resveratrol. Food Chem. 2010, 121, 23-28. [CrossRef]

39. Rezaei, A.; Tavanai, H.; Nasirpour, A. Fabrication of electrospun almond gum/PVA nanofibers as a thermostable delivery system for vanillin. Int. J. Biol. Macromol. 2016, 91, 536-543. [CrossRef] [PubMed]

40. Rezaei, A.; Nasirpour, A.; Tavanai, H.; Fathi, M. A study on the release kinetics and mechanisms of vanillin incorporated in almond gum/polyvinyl alcohol composite nanofibers in different aqueous food simulants and simulated saliva. Flavour Fragr. J. 2016, 31, 442-447. [CrossRef]

41. Noshad, M.; Mohebbi, M.; Koocheki, A.; Shahidi, F. Microencapsulation of vanillin by spray drying using soy protein isolate-maltodextrin as wall material. Flavour Fragr. J. 2015, 30, 387-391. [CrossRef]

42. Chen, Y.; Wu, Q.; Zhang, Z.; Yuan, L.; Liu, X.; Zhou, L. Preparation of curcumin-loaded liposomes and evaluation of their skin permeation and pharmacodynamics. Molecules 2012, 17, 5972-5987. [CrossRef] [PubMed]

43. Belyagoubi-Benhammou, N.; Belyagoubi, L.; El Zerey-Belaskri, A.; Atik-Bekkara, F. In vitro antioxidant properties of flavonoid fractions from Pistacia atlantica Desf. subsp. atlantica fruit using five techniques. J. Mater. Environ. Sci. 2015, 6, 1118-1125.

44. Ali, S.S.; Kasoju, N.; Luthra, A.; Singh, A.; Sharanabasava, H.; Sahu, A.; Bora, U. Indian medicinal herbs as sources of antioxidants. Food Res. Int. 2008, 41, 1-15. [CrossRef]

45. Prieto, P.; Pineda, M.; Aguilar, M. Spectrophotometric quantitation of antioxidant capacity through the formation of a phosphomolybdenum complex: Specific application to the determination of vitamin E. Anal. Biochem. 1999, 269, 337-341. [CrossRef] [PubMed]

46. Tusevski, O.; Kostovska, A.; Iloska, A.; Trajkovska, L.; Simic, S.G. Phenolic production and antioxidant properties of some Macedonian medicinal plants. Cent. Eur. J. Biol. 2014, 9, 888-900. [CrossRef]

47. Chevolleau, S.; Mallet, J.F.; Ucciani, E.; Gamisans, J.; Gruber, M. Antioxidant activity in leaves of some mediterranean plants. J. Am. Oil Chem. Soc. 1992, 69, 1269-1271. [CrossRef]

48. Jayaprakasha, G.K.; Jaganmohan Rao, L.; Sakariah, K.K. Antioxidant activities of curcumin, demethoxycurcumin and bisdemethoxycurcumin. Food Chem. 2006, 98, 720-724. [CrossRef]

49. Saito, H.; Ishihara, K. Antioxidant activity and active sites of phospholipids as antioxidants. J. Am. Oil Chem. Soc. 1997, 74, 1531-1536. [CrossRef]

50. Bandarra, N.M.; Campos, R.M.; Batista, I.; Nunes, M.L.; Empis, J.M. Antioxidant synergy of alpha-tocopherol and phospholipids. J. Am. Oil Chem. Soc. 1999, 76, 905-913. [CrossRef]

51. Safafar, H.; van Wagenen, J.; Møller, P.; Jacobsen, C. Carotenoids, phenolic compounds and tocopherols contribute to the antioxidative properties of some microalgae species grown on industrial wastewater. Mar. Drugs 2015, 13, 7339-7356. [CrossRef] [PubMed]

52. Tavassoli-Kafrani, E.; Goli, S.A.H.; Fathi, M. Fabrication and characterization of electrospun gelatin nanofibers crosslinked with oxidized phenolic compounds. Int. J. Biol. Macromol. 2017, 103, 1062-1068. [CrossRef] [PubMed]

53. Yakub, G.; Toncheva, A.; Manolova, N.; Rashkov, I.; Kussovski, V.; Danchev, D. Curcumin-loaded poly(L-lactide-co-D,L-lactide) electrospun fibers: Preparation and antioxidant, anticoagulant, and antibacterial properties. J. Bioact. Compat. Polym. 2014, 29, 607-627. [CrossRef]

54. Neo, Y.P.; Ray, S.; Jin, J.; Gizdavic-Nikolaidis, M.; Nieuwoudt, M.K.; Liu, D.; Quek, S.Y. Encapsulation of food grade antioxidant in natural biopolymer by electrospinning technique: A physicochemical study based on zein-gallic acid system. Food Chem. 2013, 136, 1013-1021. [CrossRef] [PubMed] 
55. Aytac, Z.; Kusku, S.I.; Durgun, E.; Uyar, T. Encapsulation of gallic acid/cyclodextrin inclusion complex in electrospun polylactic acid nanofibers: Release behavior and antioxidant activity of gallic acid. Mater. Sci. Eng. C 2016, 63, 231-239. [CrossRef] [PubMed]

56. Sampath, M.; Lakra, R.; Korrapati, P.; Sengottuvelan, B. Curcumin loaded poly (lactic-co-glycolic) acid nanofiber for the treatment of carcinoma. Colloids Surf. B Biointerfaces 2014, 117, 128-134. [CrossRef] [PubMed]

57. Korsmeyer, R.W.; Gurny, R.; Doelker, E.; Buri, P.; Peppas, N.A. Mechanisms of solute release from porous hydrophilic polymers. Int. J. Pharm. 1983, 15, 25-35. [CrossRef]

58. Wongsasulak, S.; Pathumban, S.; Yoovidhya, T. Effect of entrapped $\alpha$-tocopherol on mucoadhesivity and evaluation of the release, degradation, and swelling characteristics of zein-chitosan composite electrospun fibers. J. Food Eng. 2014, 120, 110-117. [CrossRef]

59. Hunley, M.T.; McKee, M.G.; Long, T.E. Submicron functional fibrous scaffolds based on electrospun phospholipids. J. Mater. Chem. 2007, 17, 605. [CrossRef]

Sample Availability: Not available.

(c) 2017 by the authors. Licensee MDPI, Basel, Switzerland. This article is an open access article distributed under the terms and conditions of the Creative Commons Attribution (CC BY) license (http:/ / creativecommons.org/licenses/by/4.0/). 